This is an electronic reprint of the original article. This reprint may differ from the original in pagination and typographic detail.

\author{
Author(s): Aartolahti, Eeva; Häkkinen, Arja; Lönnroos, Eija; Kautiainen, Hannu; Sulkava, Raimo; \\ Hartikainen, Sirpa
}

Title: $\quad$ Relationship between functional vision and balance and mobility performance in community-dwelling older adults

Year: $\quad 2013$

Version:

Please cite the original version:

Aartolahti, E., Häkkinen, A., Lönnroos, E., Kautiainen, H., Sulkava, R., \& Hartikainen, S. (2013). Relationship between functional vision and balance and mobility performance in community-dwelling older adults. Aging Clinical and Experimental Research, 25(5), 545-552. https://doi.org/10.1007/s40520-013-0120-z

All material supplied via JYX is protected by copyright and other intellectual property rights, and duplication or sale of all or part of any of the repository collections is not permitted, except that material may be duplicated by you for your research use or educational purposes in electronic or print form. You must obtain permission for any other use. Electronic or print copies may not be offered, whether for sale or otherwise to anyone who is not an authorised user. 


\title{
Relationship between functional vision and balance and mobility performance in community-dwelling older adults
}

\author{
Eeva Aartolahti ${ }^{1}$, Arja Häkkinen ${ }^{1,2}$, Eija Lönnroos ${ }^{3,4}$, Hannu Kautiainen ${ }^{5,6}$, Raimo \\ Sulkava $^{4,7}$, Sirpa Hartikainen ${ }^{3,8}$
}

${ }^{1}$ Department of Health Sciences, University of Jyväskylä, Jyväskylä, Finland

${ }^{2}$ Department of Physical and Rehabilitation Medicine, Central Finland Health Care District, Jyväskylä, Finland

${ }^{3}$ Kuopio Research Centre of Geriatric Care, University of Eastern Finland, Kuopio, Finland ${ }^{4}$ Institute of Public Health and Clinical Nutrition, Department of Geriatrics, University of Eastern Finland, Kuopio, Finland

${ }^{5}$ Unit of Primary Health Care, Helsinki University Central Hospital, Helsinki, Finland

${ }^{6}$ Department of General Practice, University of Helsinki, Helsinki, Finland

${ }^{7}$ Department of Neurology, Kuopio University Hospital, Kuopio, Finland

${ }^{8}$ School of Pharmacy, University of Eastern Finland, Kuopio, Finland

Address correspondence to Eeva Aartolahti, Department of Health Sciences, P.O. Box 35 (LL), FIN 40014 University of Jyväskylä, Finland; Email: eeva.m.aartolahti@jyu.fi; Phone: +358408053545

Key Words: Aging, vision screening, postural balance, mobility limitation, accidental falls

Running head: Functional vision and balance and mobility 


\section{ABSTRACT}

Background and Aims: Vision is an important prerequisite for balance control and mobility. The role of objectively measured visual functions has been previously studied but less is known about associations of functional vision. That refers to selfperceived vision-based ability to perform daily activities. The aim was to investigate the relationship between functional vision and balance and mobility performance in a community-based sample of older adults.

Methods: This study is part of a Geriatric Multidisciplinary Strategy for the Good Care of the Elderly project (GeMS). Participants (576) aged 76 to 100 years (mean age 81 years, 70\% women) were interviewed using a seven-item functional vision questionnaire (VF-7). Balance and mobility were measured by the Berg balance scale (BBS), timed up and go (TUG), chair stand test, and maximal walking speed. In addition self-reported fear of falling, depressive symptoms (15-item Geriatric Depression Scale), cognition (Mini Mental State Examination) and physical activity (Grimby) were assessed. In the analysis, participants were classified into poor, moderate, or good functional vision groups.

Results The poor functional vision group $(n=95)$ had more comorbidities, depressed mood, cognition decline, fear of falling, and reduced physical activity compared to participants with moderate ( $n=222)$ or good functional vision ( $n=259)$. Participants with poor functional vision performed worse on all balance and mobility tests. After adjusting for gender, age, chronic conditions, and cognition, the linearity remained statistically significant between functional vision and BBS ( $p=0.013)$, TUG $(p=0.010)$, 
and maximal walking speed $(p=0.008)$, but not between functional vision and chair stand $(p=0.069)$.

Conclusion Poor functional vision is related to weaker balance and mobility performance in community-dwelling older adults. This highlights the importance of widespread assessment of health, including functional vision, to prevent balance impairment and maintain independent mobility among older population. 


\section{INTRODUCTION}

Aging is associated with increasing prevalence of ocular diseases, and decline in different aspects of vision and vision-related functioning (Brabyn et al. 2001). Despite these changes, the importance of vision to maintain postural control seems to increase with age (Woollacott 2000). Vision also plays an important role in mobility performance (Salive et al. 1994). Therefore it is not surprising that impaired vision has been reported as a major risk factor for falls among older adults (Lord 2006).

Among older adults the assessment of visual acuity alone may underestimate the degree of disability related to vision impairment because considerable changes may occur in visual functions other than acuity (Brabyn et al. 2001). Many of these objectively measurable visual functions have found to associate with balance and mobility performance. In community-settings loss in contrast sensitivity RW.ERRORRW.ERROR(Lord and Menz 2000; Tiedemann et al. 2005; West et al. 2002a; West et al. 2002b), stereopsis (Lord and Menz 2000), visual fields (West et al. 2002a; Patel et al. 2006) as well as visual acuity (West et al. 2002b) have been associated with impaired postural control or mobility. However, less is known about interactions between these different types of vision impairment (Dhital et al. 2010). In addition, objective measurements of visual functions do not take into account the role of environmental, task-specific and individual factors affecting performance (Woollacott and Shumway-Cook 1990). For example, daily functioning of older adults may take place under less-than-optimal conditions of lighting and contrast (Sinoo et al. 2011). Furthermore, there may be great differences in abilities to compensate vision impairment with other resources such as muscle strength, balance and 
reaction time to maintain safe and independent mobility (Lord and Menz 2000; Tiedemann et al. 2005). Therefore assessment of visual functioning has been approached from different perspectives. A clear distinction has been drawn between objectively measured visual functions, i.e. how the eye functions, and functional vision, i.e. how vision deficits may affect functioning in daily and social activities (Colenbrander 2010).

Several functional vision questionnaires have been developed to measure vision impairment caused by cataracts (Massof and Ahmadian 2007). Later assessments of self-rated functional vision were proposed to be useful for vision screening of community-dwelling older adults (Valbuena et al. 1999) and for assessing their risk of falling (Kamel et al. 2000). Thus far, however, the relationship between self-rated functional vision and physical functioning has not been evaluated using well established physical performance tests (Hidalgo et al. 2009). The aim of this crosssectional study was to investigate whether there is a relationship between self-rated functional vision and objective measures of balance and mobility among older adults living in community. 


\section{METHODS}

\section{Study design and participants}

The data of the present cross-sectional study were drawn from the Geriatric Multidisciplinary Strategy for the Good Care of the Elderly project (GeMS). This was a population-based randomized comparative study conducted in the city of Kuopio, Finland from 2004 to 2007 . The objective of the GeMS study was to evaluate a model for geriatric assessment, care, and rehabilitation. The study is described in more detailed in previous study (Lihavainen et al. 2012). A random sample of 1,000 persons (500 each in the intervention and comparison groups) was selected from all the inhabitants of Kuopio aged $\geqslant 75$ years in November $2003(n=5615)$. The present study used cross-sectional data from the year 2005, when the seven-item visual function index (VF-7) was used for the first time in the GeMS study. A multidisciplinary intervention, focused on medication, nutrition, and exercise, had started during the preceding year. Of the original sample of 1,000 persons, 717 were examined in 2005. Losses from the study were due to 164 refusals, two participants who moved away, 116 deaths, and one person who could not be reached before the scheduled examination. Residents of long term-care facilities were excluded from the present study $(n=72)$. To ensure the reliability of the assessments, we further excluded 40 people who scored 17 or less on the mini-mental state examination (MMSE). In addition, participants were excluded if they had missing data on the VF-7 $(n=4)$ or on all of the balance and mobility tests $(n=25)$. Thus the final study population comprised 576 community-dwelling participants. The Research Ethics Committee of Northern Savo Hospital District and Kuopio University Hospital 
approved this study, and all of the participants gave their written informed consent prior to participation in the study.

\section{Data collection}

Three trained nurses, two physiotherapists, and two physicians were responsible for the data collection for the present study. Data collection was supplemented by a caregiver interview if a participant had difficulty answering the questions. The balance and mobility measurements were done by the physiotherapists. If the participant was unable to visit the outpatient clinic, the measurements and interviews took place in the participant's home.

\section{Balance and mobility}

The Berg balance scale (BBS) was used to assess balance by observing the participant performing 14 different functional activities (Berg et al. 1992). The overall score range is 0 (severely impaired) to 56 points (excellent). The timed up and go test (TUG) was used to assess balance and basic mobility skills (Podsiadlo and Richardson 1991). The patients were instructed to stand up from a chair, walk for a distance of $3 \mathrm{~m}$ at maximal speed, turn, walk back, and sit down on the chair. A modified chair stand test (Guralnik et al. 1994) was used to assess the ability of participants to perform sit-to-stand and stand-to-sit tasks five times as fast as possible. As a modification of the original test, hands were held to each side and participants were allowed to help with their hands if needed. Maximal walking speed $(\mathrm{m} / \mathrm{s})$ was measured for a $10 \mathrm{~m}$ distance. Two markers were used to indicate the 
start and finish of the $10 \mathrm{~m}$ path. Participants started walking $2 \mathrm{~m}$ before the first mark and were instructed to continue walking past the end mark for a further $2 \mathrm{~m}$, so that they were walking at their maximal pace within the timed $10 \mathrm{~m}$ path.

Performance measurements were always done in a same order. Each test was performed once. If the participant didn't seem to fully understand the instructions, the tester repeated those once. The flooring was standardized so that all balance and mobility tests were conducted on a rigid floor surface. The participants had shoes on except in BBS. For all of the timed tests time was measured with a stopwatch, and use of a walking aid was allowed $(n=81)$ in the TUG and maximal walking speed tests.

\section{Functional vision}

Functional vision was assessed by the VF-7, a modified version of the VF-14 (Steinberg et al. 1994). The VF-7 comprises seven activities dependent on functional vision and is validated for use in patients with cataracts (Uusitalo et al. 1999). Patients are asked how much difficulty they have doing each activity, with or without glasses. The activities are reading small print; seeing steps, stairs, or curbs; reading traffic, street, or store signs; doing fine handwork; cooking; watching television and driving in darkness. Each question is scored as follows: 4, 3, 2, or 1, respectively, if the subject has no, little, moderate, or a great deal of difficulty performing the activity, and 0 if the subject is unable to perform the activity due to lack of vision. An item is not included in the scoring if the patient does not do the activity for reasons other than his or her vision. The score is obtained by averaging responses across all activities and multiplying by 25 . Scores range from 0 (representing maximum 
impairment) to 100 (representing no impairment). The response rate varied between $97 \%$ and $100 \%$ for all other VF-7 questions, but was lower for the questions about cooking $(n=519,90 \%)$ and driving in darkness $(n=99,17 \%)$. Only 114 participants had a valid driving license, and the gender distribution of the respondents for the question about driving in darkness was uneven (16 women and 83 men). Thus, the question was dropped from the final index.

For analytical purposes, participants were categorized into three groups according to their VF-7 results: (1) poor functional vision, VF-7 score $\leqslant 75,(n=95)$; (2) moderate functional vision, scores between 75 and 100, $(n=222)$; and (3) good functional vision, the score of $100(n=259)$. The cut-off value between poor and moderate functional vision groups (VF-7 score $=75$ ) represented a sum score in a theoretical situation in which participant stated they had little difficulties (score 3) with all of the activities in question.

\section{Health status}

Cognitive function was assessed using the MMSE (Folstein et al. 1975) and depressive symptoms were assessed using the 15-item Geriatric Depression Scale (GDS-15) (Sheikh and Yesavage 1986). Body mass index (BMl, $\mathrm{kg} / \mathrm{m}^{2}$ ) was calculated from body weight and height measured by the study nurses. The use of medication was self-reported by participants, and was verified against prescription forms, drug containers and medical records. Ocular status was defined by interviewing the participants and verifying the information and diagnoses against medical records. In addition, glaucoma diagnoses were verified from the Special Reimbursement Register (maintained by the Social Insurance Institution of Finland). 
Comorbidity was computed using a modified functional comorbidity index $(\mathrm{FCl})$, which is a validated scale that predicts physical function in older adults (Groll et al. 2005). The FCl takes into account the number of medical conditions, with higher scores indicating greater comorbidity. In this study, data on the following medical conditions were available: rheumatoid arthritis and other connective tissue diseases, osteoporosis, chronic asthma or chronic obstructive pulmonary disease (COPD), coronary artery disease, heart failure, myocardial infarction, Parkinson's disease or multiple sclerosis, stroke, diabetes, depression, visual impairment, hearing impairment, and obesity $(\mathrm{BMI}>30)$. Patient diagnoses obtained from the Special Reimbursement Register were used to screen for the presence of rheumatoid arthritis and other connective tissue diseases, chronic asthma or COPD, Parkinson's disease, and multiple sclerosis. For the purposes of this study, the FCl item of visual impairment (i.e., presence of an eye disease that could potentially impair eyesight) was omitted.

\section{Fear of falling, self-rated mobility and physical activity}

Participants' fear of falling was investigated by asking them the question "Does fear of falling restrict your everyday locomotion?" The possible answers were: no; yes, outdoors in slippery conditions; yes, outdoors in winter; yes, outdoors year-round; or yes, indoors). In the analysis, the "yes" responses were combined under the single response "yes." Self-rated mobility was assessed by asking whether respondents could walk 400 m (yes; yes, with difficulty, but without help; not without help; or no). In the analysis, the categories "yes" and "yes, with difficulty, but without help" were combined under the single category "yes independently". The level of physical 
activity was assessed using a modified version of the scale by Grimby (Grimby 1986). The participants were categorized on the basis of their self-rated physical activity into a low-activity group (no other exercise, at most light walking 1-2 times/week), a moderate-activity group (light walking or other light exercise several times a week or moderate exercise 1-2 times/week), or an active group (moderate or vigorous exercise several times/wk).

\section{Statistics}

Variables with normal distribution descriptive values were expressed by means and standard deviations (SD); statistical comparison between the groups was made by using analysis of variance (ANOVA). Variables with ordinal descriptive values were expressed by median and interquartile range (IQR); statistical comparison between groups was made by using Kruskal-Wallis test. Measures with a discrete distribution are expressed as counts (\%) and analyzed by Chi-Square. Statistical significance for the hypotheses of linearity (orthogonal polynomial in the level of functional vision group values, linear trends) for physical performance was evaluated by bootstraptype analysis of covariance (ANCOVA); because of the violation of distributions assumptions. Age, gender, $\mathrm{FCl}$ and MMSE scores were used as covariates in the ANCOVA analyses. The normality of the variables was tested using the Shapiro-Wilk W-test. The $\alpha$-level was set at 0.05 . Stata statistical software, release 12.1 (StataCorp, College Station, Texas, USA), was used for the analyses. 


\section{RESULTS}

Of the 576 participants in the present study, $70 \%(n=402)$ were women and the mean age of the participants was 81 years (range $76-100$ years). The mean (SD) VF-7 index for the whole study group was 88.2 (18.7); 88.4 (20.9) for men and 88.1 (20.1) for women.

The characteristics of the participants, grouped by level of functional vision, are shown in Table 1. Groups differed significantly with regard to all demographic, health and activity characteristics except for gender and BMI. The participants in the poor functional vision group were older and their years of education were fewer compared to those with moderate or good functional vision. Participants with poor functional vision had higher $\mathrm{FCl}$ scores and a higher number of medicines, and they were more likely to have macular degeneration, glaucoma, a lower limb endoprosthesis or history of hip fracture. They also had lower MMSE and higher GDS-15 scores. Additionally, participants in the poor functional vision group were less physically active, less often able to walk $400 \mathrm{~m}$ independently, and more often had a fear of falling compared to those with moderate or good functional vision.

The mean performance in poor, moderate and good functional vision groups for BBS was 43 ( $95 \% \mathrm{Cl}$ : 41 to 45 ), 48 ( 47 to 49 ), 50 (49 to 51 ) points; for chair stand 18.2 (15.9 to 20.4), 15.2 (14.2 to 16.2 ), 14.6 (13.9 to 15.2 ) seconds; for TUG 17.3 (14.9 to 19.7), 12.9 (11.9 to 13.9), 11.7 (10.9 to 12.6) seconds and for walking speed 1.08 (0.97 to 1.19$), 1.28$ (1.22 to 1.34$), 1.41$ (1.35 to 1.47$) \mathrm{m} / \mathrm{s}$ respectively. The linear relationships between self-rated functional vision and BBS $(p<0.001)$, TUG $(p<$ $0.001)$, walking speed $(p<0.001)$ and chair stand $(p=0.0089)$ were statistically significant. After adjusting for gender, age, $\mathrm{FCl}$, and MMSE scores, the linearity 
remained statistically significant between functional vision and BBS $(p=0.013)$, TUG ( $p=0.010)$, and walking speed $(p=0.008)$, but not between functional vision and chair stand $(p=0.069)$ (Figure 1). 


\section{DISCUSSION}

This cross-sectional study found a significant relationship between functional vision and objectively measured balance and mobility performance among communitydwelling people aged $\geqslant 76$ years. The average results of balance and mobility tests were significantly poorer among persons with poor functional vision compared to those with moderate or good functional vision. After adjusting for gender, age, cognition and comorbidity, linear association still remained significant for BBS, TUG and walking speed but not for chair stand results.

The level of balance and mobility performance that older adults with poor functional vision achieved in this study may have harmful consequences. Adequate vision is important for maintaining balance and detecting and avoiding hazards in the environment (Patla 1997). In earlier studies, older adults with BBS scores of $<46$ were more likely to develop ADL difficulty over an 18-month period (Wennie Huang et al. 2010), and they were at increased risk for multiple falls if their BBS score was $<45$ (Muir et al. 2008). For the TUG test was reported that performance time of $>14$ seconds (Shumway-Cook et al. 2000) predicted higher risks of falling. In addition, a walking speed of at least $1.2 \mathrm{~m} / \mathrm{s}$ is generally required to cross the road safely during a green light (Finnish Road Administration 2005). In our study, the participants with poor functional vision performed below all of these cut-off levels indicating that risk factors for disability and future falls seem to accumulate.

It has been previously found that in addition to detecting hazards in the environment, vision plays an important role in maintaining stability when standing or moving (Patla 1997). Thus, it appears that good vision provides support for safely and quickly undertaking the chair stand test (Lord et al. 2002). In this study an independent 
association between functional vision and chair stand test performance was not found. In a previous study, chair stand test performance was weakened only among persons with more severe visual impairments compared to walking speed, stair climbing, and tandem standing tests where problems occurred already with milder visual impairments (Laitinen et al. 2007). Compared with other physical performance tests used in the present study, the chair stand is less demanding in terms of balance control and vision because no navigation in the environment is needed (Patla 1997). The sit-to-stand performance is though influenced by visual function, particularly contrast sensitivity, but there are several other factors associated with the test time, the most important being quadriceps strength (Lord et al. 2002). Consequently, in the chair stand test older adults may to some extend better compensate their visual limitations than in the other tests used here.

The found cross sectional association between functional vision and balance and mobility performance may have several explanations. Independent and safe mobility is a complex action where movement emerges from an interaction between the individual, the task, and the environment (Woollacott and Shumway-Cook 1990). On individual level postural control of stance and locomotion requires function of motor, sensory, and cognitive systems, which all are affected by aging (Woollacott 2000). In addition to these physiological changes, declines in health including number of comorbidities, depressiveness and memory problems were common in the poor functional vision group. These results are consistent with the findings of previous studies in which depression (Iliffe et al. 2005) and cognitive decline (Lin et al. 2004) were more prevalent among older adults with poor functional vision. Thus, strategies to compensate for the effects of vision impairment were more limited among persons with poor functional vision (Horak 2006). This idea suggests that the role of vision in 
balance and mobility performance may become even more critical in old age when health problems tend to accumulate.

One possible explanation for weaker balance and mobility performance might be the avoidance of physical activity due reduced functional vision. Our findings of low physical activity and fear of falling among the participants with poor functional vision was concordant with the findings of Kempen et al. (2009). Poor vision is a wellestablished risk factor for falling among older adults (Lord 2006); a functional vision index, the Activities of Daily Vision Scale, has been reported to be a useful tool to assess falling risk in older adults (Kamel et al. 2000). A cause-and-effect relations cannot be concluded because of the cross-sectional design of the present study, but previous longitudinal studies support the default hypothesis that poor functional vision is a predisposing factor for development of fear of falling (Murphy et al. 2003), and fear-related avoidance of physical activity predicts declines in balance and mobility performance (Deshpande et al. 2008). Characteristics of participants in this study are parallel to this idea: history of hip fractures, fear of falling, impaired ability to walk $400 \mathrm{~m}$, and low physical activity were more prevalent among participants with poor functional vision.

Vision impairment and vision-related balance and mobility limitations seem to weaken ability and willingness to be physically active. Decreasing physical activity may speed up sarcopenia and muscle strength especially after age of 75 years (Mitchell et al. 2012). Older adults share numerous overlapping pathways and risk factors for disability such as decreasing physical function, increasing number of chronic medical conditions and impaired vision (Rosso et al. 2013). Thus both multifaceted assessment and rehabilitation of balance and mobility performance are important components of disability prevention among visually impaired older adults. 


\section{Strengths and limitations}

A major strength of this study is that it comprised a large representative population sample of community-dwelling older adults aged $76-100$ years. Another strength is the use of objective and valid measures of balance and mobility performance. In addition the measures were conducted by physiotherapists who were familiar with and well educated to these tests. Furthermore, the sample was probably more representative of the general population of people aged $76-100$ years than those in previous studies, because the interviews and measurements were done at participants' homes if they were unable to come to the study clinic. Thus, more frail community-dwelling subjects were included in the study. Cognition had some impact on reliable self-assessment and on understanding and retaining the instructions. We tried to minimize the confounding effect of cognitive impairment on the participants' self-rating of their functional vision by excluding the participants with the lowest MMSE scores ( $(17)$ and adjusting the analysis with MMSE scores.

This study also has some limitations. Due the cross-sectional design, causal inferences cannot be made. In addition, the generalizability of the results may be limited, because we excluded the frailest participants, who were unable to perform balance and mobility tests, and the participants residing in institutional care. Any population based cut-off scores for VF-7 has not been established and therefore we needed to base the grouping in a theoretical cut-off scores. Further, the present data was not collected at the baseline of the intervention study, but one year later. The multidisciplinary intervention, focused on medication, nutrition, and exercise, had started gradually during the preceding year. As part of the exercise counseling 
intervention, 153 participants had started weekly strength and balance training at the gym during the fall of 2004 or the year 2005 before the assessments. However, the assessment of functional vision and the physical performance measurements were made cross sectionally without any time disparity. The VF-7 and the original VF-14 questionnaires were designed to allow clinical practices to assess severely impaired populations. In this population-based sample, $45 \%$ of the participants had no visual impairment (full score on VF-7); thus, a ceiling effect was notable. In populationbased studies, questionnaire items that are seldom answered must be considered (Valbuena et al. 1999); in our study, this resulted in the driving at night question being dropped from the final index. The findings of the present study suggest that the relevance of functional vision items to community-dwelling older adults should be carefully considered.

In conclusion, poor functional vision was related to worse performance in balance and mobility tests among community-dwelling older adults. Poor functional vision often coexisted with other health problems but there was also linear association independent of gender, age and comorbidity between the functional vision and performance in balance and mobility tests. This indicates a need for widespread assessment of health, including functional vision, when aiming to prevent balance impairment and mobility limitations, as well as falls and disabilities, in older adults. 
ACKNOWLEDGMENTS

The GeMS study was financed by the Finnish Social Insurance Institution and the city of Kuopio, Finland. This study was supported in part by the Juho Vainio Foundation, Finland. The authors declare no conflicts of interest. We thank the participants and the research staff of the GeMS study. 


\section{REFERENCES}

Berg KO, Wood-Dauphinee SL, Williams JI, Maki B (1992) Measuring balance in the elderly: Validation of an instrument. Can J Public Health 83 Suppl 2:S7-11

Brabyn J, Schneck M, Haegerstrom-Portnoy G, Lott L (2001) The smith-kettlewell institute (SKI) longitudinal study of vision function and its impact among the elderly: An overview. Optom Vis Sci 78:264-269

Colenbrander A (2010) Assessment of functional vision and its rehabilitation. Acta Ophthalmol.88:163-173. doi: 10.1111/j.1755-3768.2009.01670.x

Deshpande N, Metter EJ, Lauretani F, Bandinelli S, Guralnik J, Ferrucci L (2008) Activity restriction induced by fear of falling and objective and subjective measures of physical function: A prospective cohort study. J Am Geriatr Soc 56:615-620. 10.1111/j.1532-5415.2007.01639.x

Dhital A, Pey T, Stanford MR (2010) Visual loss and falls: A review. Eye 24:14371446. doi: $10.1038 /$ eye. 2010.60

Finnish Road Administration (2005) Liikennevalojen suunnittelu, LIVASU. (Planning the directing of traffic lights, in Finnish). Helsinki: Tiehallinto.

Folstein MF, Folstein SE, McHugh PR (1975) "Mini-mental state". A practical method for grading the cognitive state of patients for the clinician. J Psychiatr Res 12:189-198 
Grimby G (1986) Physical activity and muscle training in the elderly. Acta Med Scand Suppl. 711:233-237

Groll DL, To T, Bombardier C, Wright JG (2005) The development of a comorbidity index with physical function as the outcome. J Clin Epidemiol 58:595-602

Guralnik JM, Simonsick EM, Ferrucci L, Glynn RJ, Berkman LF, Blazer DG et al (1994) A short physical performance battery assessing lower extremity function: Association with self-reported disability and prediction of mortality and nursing home admission. J Gerontol 49:M85-94

Hidalgo JL, Martinez IP, Bravo BN, Pretel FA, Ferrer AV, Verdejo MA (2009) Visual function versus visual acuity in older people. Ophthalmic Epidemiol 16:262-268. doi: $10.3109 / 09286580902999397$

Horak FB (2006) Postural orientation and equilibrium: What do we need to know about neural control of balance to prevent falls? Age Ageing 35 Suppl 2:ii7-ii11

lliffe S, Kharicha K, Harari D, Swift C, Gillmann G, Stuck A (2005) Self-reported visual function in healthy older people in britain: An exploratory study of associations with age, sex, depression, education and income. Fam Pract 22:585-590

Kamel HK, Guro-Razuman S, Shareeff M (2000) The activities of daily vision scale: A useful tool to assess fall risk in older adults with vision impairment. J Am Geriatr Soc $48: 1474-1477$

Kempen Gl, van Haastregt JC, McKee KJ, Delbaere K, Zijlstra GA (2009) Sociodemographic, health-related and psychosocial correlates of fear of falling and 
avoidance of activity in community-living older persons who avoid activity due to fear of falling BMC Public Health 9:170. doi:10.1186/1471-2458-9-170

Laitinen A, Sainio P, Koskinen S, Rudanko SL, Laatikainen L, Aromaa A (2007) The association between visual acuity and functional limitations: Findings from a nationally representative population survey. Ophthalmic Epidemiol 14:333-342

Lihavainen K, Sipila S, Rantanen T, Seppänen J, Lavikainen P, Sulkava R, Hartikainen S (2012) Effects of comprehensive geriatric intervention on physical performance among people aged 75 years and over Aging Clin Exp Res 24:331338

Lin MY, Gutierrez PR, Stone KL, Yaffe K, Ensrud KE, Fink HA et al (2004) Vision impairment and combined vision and hearing impairment predict cognitive and functional decline in older women. J Am Geriatr Soc 52:1996-2002

Lord SR (2006) Visual risk factors for falls in older people. Age Ageing 35 Suppl 2:ii42-5

Lord SR, Murray SM, Chapman K, Munro B, Tiedemann A (2002) Sit-to-stand performance depends on sensation, speed, balance, and psychological status in addition to strength in older people. J Gerontol A Biol Sci Med Sci 57:M539-543

Lord SR, Menz HB (2000) Visual contributions to postural stability in older adults. Gerontology 46:306-310

Massof RW, Ahmadian L (2007) What do different visual function questionnaires measure? Ophthalmic Epidemiol 14:198-204. doi: 10.1080/09286580701487883 
Mitchell WK, Williams J, Atherton P, Larvin M, Lund J, Narici M (2012) Sarcopenia, dynapenia, and the impact of advancing age on human skeletal muscle size and strength; a quantitative review. Front Physiol 3:260. doi: 10.3389/fphys.2012.00260

Muir SW, Berg K, Chesworth B, Speechley M (2008) Use of the berg balance scale for predicting multiple falls in community-dwelling elderly people: A prospective study. Phys Ther 88:449-459. doi: 10.2522/ptj.20070271.ic

Murphy SL, Dubin JA, Gill TM (2003) The development of fear of falling among community-living older women: Predisposing factors and subsequent fall events. J Gerontol A Biol Sci Med Sci 58:M943-947

Patel I, Turano KA, Broman AT, Bandeen-Roche K, Munoz B, West SK (2006) Measures of visual function and percentage of preferred walking speed in older adults: The salisbury eye evaluation project. Invest Ophthalmol Vis Sci 47:65-71. doi: 10.1167/iovs.05-0582

Patla AE. Understanding the roles of vision in the control of human locomotion (1997) Gait Posture 5:54-69

Podsiadlo D, Richardson S (1991) The timed "up \& go": A test of basic functional mobility for frail elderly persons. J Am Geriatr Soc 39:142-148

Rosso AL, Eaton CB, Wallace R, Gold R, Stefanick ML, Ockene JK et al (2013) Geriatric syndromes and incident disability in older women: Results from the women's health initiative observational study. J Am Geriatr Soc 61:371-379. doi: $10.1111 /$ jgs. 12147 
Salive ME, Guralnik J, Glynn RJ, Christen W, Wallace RB, Ostfeld AM (1994) Association of visual impairment with mobility and physical function. J Am Geriatr Soc 42:287-292

Sheikh A, Yesavage J (1986) Geriatric Depression Scale (GDS) Recent evidence and development of a shorter version. Clin Gerontol 5:165-173

Shumway-Cook A, Brauer S, Woollacott M (2000) Predicting the probability for falls in community-dwelling older adults using the timed up \& go test. Phys Ther 80:896-903

Sinoo MM, van Hoof J, Kort HSM (2011) Light conditions for older adults in the nursing home: Assessment of environmental illuminances and colour temperature. Build Environ 46:1917-1927. doi: 10.1016/j.buildenv.2011.03.013

Steinberg EP, Tielsch JM, Schein OD, Javitt JC, Sharkey P, Cassard SD et al (1994) The VF-14. an index of functional impairment in patients with cataract. Arch Ophthalmol 112:630-638

Tiedemann A, Sherrington C, Lord SR (2005) Physiological and psychological predictors of walking speed in older community-dwelling people. Gerontology 51:390-395. doi: 10.1159/000088703

Uusitalo RJ, Brans T, Pessi T, Tarkkanen A (1999) Evaluating cataract surgery gains by assessing patients' quality of life using the VF-7. Journal of Cataract \& Refractive Surgery 25:989-994. doi: 10.1016/S0886-3350(99)00082-6 
Valbuena M, Bandeen-Roche K, Rubin GS, Munoz B, West SK (1999) Self-reported assessment of visual function in a population-based study: The SEE project. salisbury eye evaluation. Invest Ophthalmol Vis Sci 40:280-288

Wennie Huang WN, Perera S, Vanswearingen J, Studenski S (2010) Performance measures predict onset of activity of daily living difficulty in community-dwelling older adults. J Am Geriatr Soc 58:844-852. doi: 10.1111/j.1532$5415.2010 .02820 . x$

West CG, Gildengorin G, Haegerstrom-Portnoy G, Schneck ME, Lott L, Brabyn JA (2002a) Is vision function related to physical functional ability in older adults? J Am Geriatr Soc 50:136-145. doi: 10.1046/j.1532-5415.2002.50019.x

West SK, Rubin GS, Broman AT, Munoz B, Bandeen-Roche K, Turano K (2002b) How does visual impairment affect performance on tasks of everyday life? the SEE project. salisbury eye evaluation. Arch Ophthalmol 120:774-780

Woollacott $\mathrm{MH}$ (2000) Systems contributing to balance disorders in older adults. J Gerontol A Biol Sci Med Sci 55:M424-428

Woollacott MH, Shumway-Cook A (1990) Changes in posture control across the life span-A systems approach. Phys Ther 70:799-807 
Table 1 - Characteristics of participants by functional vision group $(n=576)$.

\begin{tabular}{|c|c|c|c|c|c|c|c|}
\hline \multirow{3}{*}{$\begin{array}{l}\text { Characteristic } \\
\text { Demographics }\end{array}$} & \multicolumn{4}{|c|}{ Functional vision by VF-7 score } & & & \multirow[b]{2}{*}{$p$} \\
\hline & \multicolumn{2}{|c|}{$\begin{array}{l}\text { Poor } \\
(n=95)\end{array}$} & \multicolumn{2}{|c|}{$\begin{array}{l}\text { Moderate } \\
(n=222)\end{array}$} & \multicolumn{2}{|c|}{$\begin{array}{l}\text { Good } \\
(n=259)\end{array}$} & \\
\hline & & & & & & & \\
\hline Female, $n(\%)$ & 65 & $(68)$ & 167 & $(75)$ & 170 & $(66)$ & 0.070 \\
\hline Age, mean (SD) & 84 & (5) & 81 & (4) & 80 & (4) & $<0.001$ \\
\hline BMI, mean (SD) & 27 & $(4.6)$ & 27 & $(4.4)$ & 27 & $(4.4)$ & 0.730 \\
\hline Education years, med (IQR) & 6 & $(4,8)$ & 7 & $(6,10)$ & 7 & $(6,10)$ & 0.004 \\
\hline \multicolumn{8}{|l|}{ Clinical data } \\
\hline $\mathrm{FCl}$, med (IQR) & 2 & $(1,4)$ & 2 & $(1,3)$ & 2 & $(1,3)$ & 0.001 \\
\hline Number of medicines, med (IQR) & 7 & $(4,8)$ & 5 & $(3,7)$ & 4 & $(2,6)$ & $<0.001$ \\
\hline Lower limb endoprosthesis, $n(\%)$ & 29 & $(31)$ & 41 & (18) & 45 & $(17)^{\prime}$ & 0.018 \\
\hline Hip fracture, $n(\%)$ & 8 & (8) & 9 & (4) & 4 & (2) & $<0.001$ \\
\hline MMSE, mean (SD) & 26 & (3) & 27 & (3) & 27 & (3) & $<0.001$ \\
\hline GDS-15, mean (SD) & 2.5 & $(2.5)$ & 1.7 & $(1.9)$ & 1.1 & $(1.5)$ & $<0.001$ \\
\hline \multicolumn{8}{|l|}{ Ocular status n (\%) } \\
\hline Cataracts operated & 46 & $(48)$ & 103 & $(46)$ & 103 & $(40)$ & 0.251 \\
\hline Macular degeneration & 36 & (38) & 22 & (10) & 12 & (5) & $<0.001$ \\
\hline Glaucoma & 14 & (15) & 26 & (12) & 15 & (6) & 0.015 \\
\hline \multicolumn{8}{|l|}{ Activity $n(\%)$} \\
\hline Fear of falling & 49 & $(52)$ & 57 & $(26)$ & 58 & $(22)$ & $<0.001$ \\
\hline Able to walk $400 \mathrm{~m}$ independently & 79 & (83) & 207 & (93) & 246 & (95) & $<0.001$ \\
\hline yes & 36 & $(38)$ & 129 & (58) & 177 & (68) & \\
\hline yes, with difficulty, but without help & 43 & (45) & 78 & (35) & 69 & (27) & \\
\hline Physical activity & & & & & & & $<0.001$ \\
\hline Low & 50 & $(53)$ & 70 & $(31)$ & 80 & $(31)$ & \\
\hline Mod & 36 & (38) & 95 & (43) & 110 & (42) & \\
\hline High & 9 & (9) & 57 & (26) & 69 & (27) & \\
\hline
\end{tabular}




\section{LEGEND TO FIGURE}

Fig. 1 - Mean $(95 \% \mathrm{Cl})$ of balance and mobility performance according to functional vision group. Higher score on the Berg Balance scale indicates better performance. 

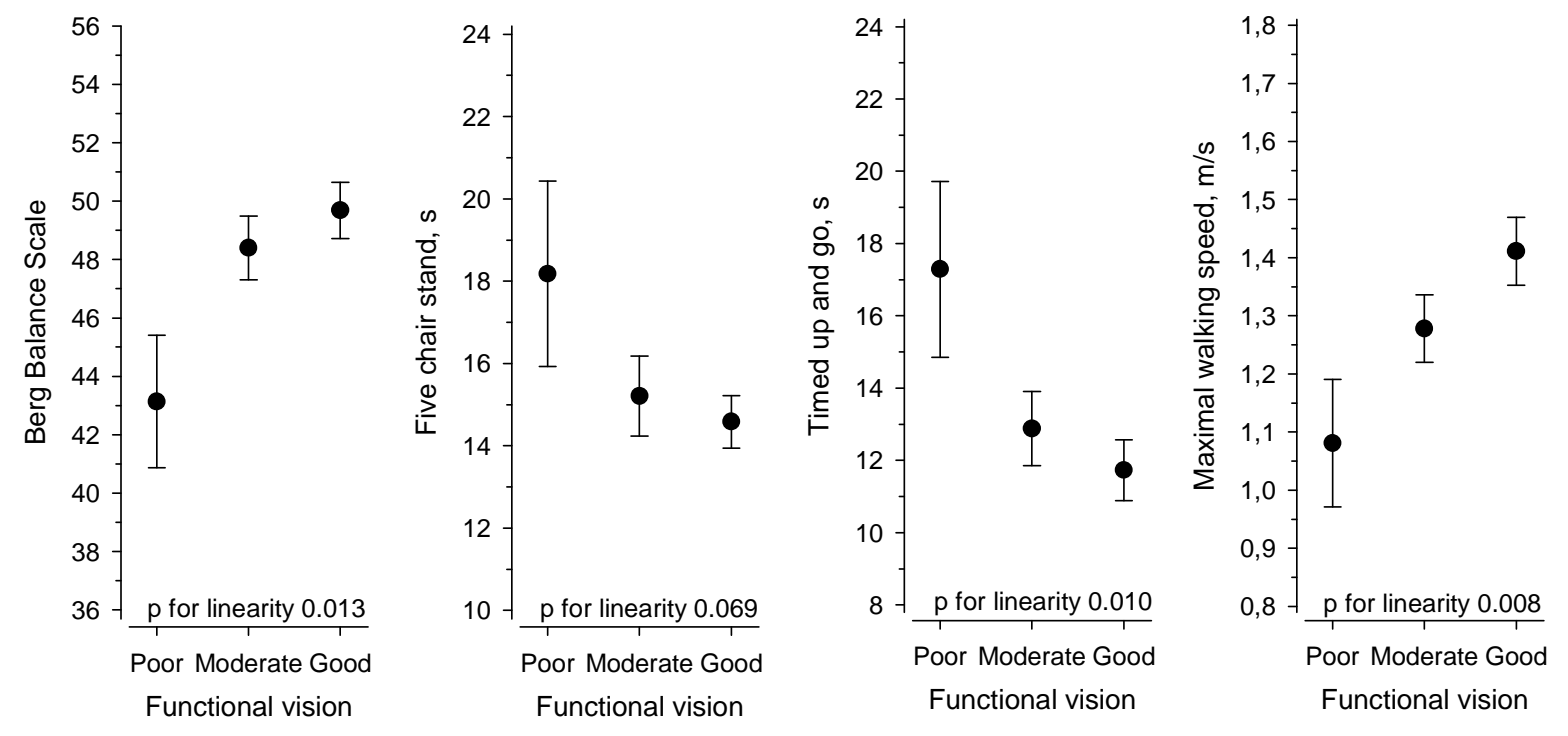